\title{
"Quero Entregar meu Bebê para Adoção": O Manejo de Profissionais da Saúde
}

\author{
Suane Pastoriza Faraj ${ }^{1}$ \\ Bruna Maria Corazza Martins \\ Samara Silva dos Santos \\ Dorian Mônica Arpini \\ Aline Cardoso Siqueira \\ Universidade Federal de Santa Maria
}

\begin{abstract}
RESUMO - O presente estudo qualitativo objetivou compreender como profissionais da saúde de hospitais públicos manejam e conduzem os casos de mães que decidem entregar o filho para adoção. Entrevistas foram realizadas com sete profissionais da área de saúde. As profissionais relataram que a maioria das mulheres que entregaram seus filhos para adoção nessas instituições possuíam baixa condição socioeconômica e não tinham realizado um bom acompanhamento pré-natal durante a gestação. As entrevistas também demonstraram suas tentativas de convencer as mães a desistir de entregar seu filho, além de sua percepção de não possuírem preparo para lidar com esses casos. Dessa forma, torna-se necessário discutir esse tema junto às equipes de saúde, como também incluir na equipe profissionais da Psicologia e do Serviço Social que possam realizar o acompanhamento da gestante e da puérpera.
\end{abstract}

Palavras-chaves: adoção, maternidade, direitos da mulher, profissionais da saúde

\section{"I Want to Give up my Baby for Adoption": The Management of Healthcare Professionals}

\begin{abstract}
This qualitative study aimed to understand how healthcare professionals of public hospitals deal with the case of mothers who decided to give their child up for adoption. Interviews were conducted with seven healthcare professionals. The professionals related that most of the women who gave their children up for adoption were from low-income conditions and they had not done a good prenatal care during pregnancy. The interviews also evidenced their attempts to convince mothers to renounce giving their children up for adoption, besides their perception that they do not have preparation to deal with such cases. Therefore, it is necessary to bring this theme into discussion in the health care teams, as well as including Psychology and Social Services professionals in the team, so that follow-up of the pregnant and puerperal women can be accomplished.
\end{abstract}

Keywords: adoption, motherhood, women's rights, health professionals

Na realidade brasileira, existem muitos casos de mulheres que abandonam seus filhos em lugares perigosos e insalubres, expondo-os ao risco de morte (Motta, 2008). Se entregar o filho para adoção na maternidade é uma atitude prevista pela legislação brasileira, por que ainda há relatos de abandono dos filhos em lugares de risco? De fato, parece ser inaceitável socialmente o fato de uma mulher entregar seu filho. Essa ideia pode estar atrelada à existência de uma forte concepção de que as mulheres nascem com a tarefa da procriação e que não lhes cabe a decisão de exercer ou não a maternidade (Badinter, 1985). Todas essas concepções, estando as pessoas cientes delas ou não, permeiam os comportamentos, os valores e as decisões inclusive dos profissionais de saúde na sua atuação .

Estudos internacionais apresentam dados valiosos sobre os sentimentos das mães que entregam seus filhos para adoção e como elas percebem o sistema de assistência social que desenvolve o trabalho de atendê-las (Aloi, 2009; Condon, 1986; Najman, Morrison, Keeping, Andersen, \& Williams, 1990). Muitos desses estudos apresentam o sofrimento vivenciado por elas em silêncio, pois esses sentimentos de luto e de perda não são acolhidos socialmente, tendo em

1 Endereço para correspondência: Av. Roraima, 1000, Prédio 74B, sala 3205, Santa Maria, RS, Brasil. CEP: 97105-900.E-mail: suanef@ yahoo.com.br vista que elas entregaram espontaneamente suas crianças. No Brasil, esse tema ainda é pouco explorado cientificamente, principalmente na área da psicologia. Em pesquisa realizada nos principais portais de busca brasileiros (tais como Scielo, Pepsic e Bvs-Psi), não foram encontrados estudos científicos que retratassem o trabalho dos profissionais de saúde com mulheres que entregam o filho para adoção na maternidade. Para que se compreenda o fenômeno, torna-se necessário discutir o mito do amor materno e a recente legislação vigente no país de proteção tanto à criança quanto à mãe.

\section{Mito do Amor Materno}

A ação de entregar um filho, em geral, não é bem vista na sociedade brasileira. Existe uma tendência de interpretar toda separação entre mãe e filho decorrente da adoção como abandono (Menezes \& Dias, 2011). Contudo, existe diferença entre abandono e entrega. $\mathrm{O}$ abandono é um tipo de maustratos que consiste em deixar o filho em qualquer lugar, sem a preocupação com sua sobrevivência. Já na entrega ou doação de um filho, há uma impossibilidade de a mãe permanecer com o filho, porém a mãe preocupa-se com seu bem-estar e sua vida (Menezes \& Dias, 2011). 
Quando ocorre a entrega ou doação de um filho na maternidade, é comum se ouvir comentários pejorativos e carregados de juízo de valor direcionados às mães que entregam o filho (Motta, 2008). Por que é tão difícil conceber a recusa de ser mãe? Por que as mulheres são julgadas tão cruelmente por entregar seus próprios filhos, sem que sua motivação seja levada em consideração? E por que, uma vez que o façam, é esperada a negação dos seus sentimentos de dor ou, por outro lado, que os vivam de forma tão intensa que as impeçam de seguir suas vidas? Esses posicionamentos sociais têm sido atribuídos ao que a pesquisadora francesa Elizabeth Badinter nomeou como mito do amor materno (Badinter, 1985).

Segundo Badinter (1985), parece haver, em nossa sociedade, a tendência de perceber a maternidade como algo instintivo, em que os sentimentos maternos são inatos e compartilhados por todas as mulheres. Em contrapartida, a concepção do "amor materno" está atrelada às mudanças históricas e sociais que se iniciaram por volta do século XVII. A compreensão da infância e dos papéis assumidos pelas mulheres foi se modificando no decorrer do tempo (Ariès, 1981; Badinter, 1985). Os registros sobre a história da infância mostram altos índices de mortalidade e de práticas de infanticídio e abandono. Apontam ainda que muitas crianças eram entregues a outra família para serem educadas, retornando à sua família após os sete anos de idade (Ariès, 1981). Nesse sentido, os documentos retratam a relação entre mãe e filho marcada por sentimentos de indiferença e desinteresse, muitas vezes, justificados pela alta possibilidade de morte da criança (Badinter, 1985). Outras mulheres, especialmente as chamadas "amas de leite" e as parteiras, eram responsáveis pelos cuidados e pela preservação da infância (Ariès, 1981). A mãe, em geral, não era comprometida com a amamentação, o cuidado e o afeto em relação ao filho, o que demonstrava que o sentimento de amor materno não estava presente como uma referência de afetividade (Ariès, 1981; Badinter, 1985).

No século XVII, devido à interferência do poder público e da igreja católica, ocorreram mudanças nos cuidados com as crianças. Os bebês e as crianças passaram a ter a atenção materna, sendo amamentados por suas mães. De acordo com Badinter (1985, p. 204), "a sobrevivência das crianças aparecia como um imperativo moral e a expressão de uma nova afeição materna". Assim, passou a existir a ideia de que os cuidados e a atenção propiciados pela mãe possibilitam o conforto e a sobrevivência do bebê. Nesse contexto, houve um reconhecimento de "um novo amor" pelo bebê, sendo manifestado pelo cuidado com a higiene e a saúde, pelo uso de vestimentas adequadas, bem como pela manifestação de sentimentos de afetividade e dedicação da mãe para com a criança (Badinter 1985).

Devido a motivos econômicos, sociais e religiosos, na França, no final do século XVIII, o mito do amor materno foi colocado em primeiro plano. Era preciso manter a mulher no ambiente familiar. Assim, o dever das mulheres estava voltado para a procriação e o cuidado dos filhos. Especialistas, entre eles, médicos e teólogos, começaram a abordar o amor materno como insubstituível, enfocando-o como natural e instintivo a toda mulher (Motta, 2008).
A importância do cuidado materno se destacou nos séculos XIX e XX devido à responsabilidade delegada à mãe de assumir o papel de educadora do filho, sendo responsável pelo seu desenvolvimento emocional (Ariès, 1981). A psicanálise enfatizou a importância do cuidado e amor materno para o desenvolvimento e a saúde mental da criança. Autores como Winnicott (1987/1999) e Bowlby (1988/1989) abordaram a relação mãe-bebê, enfatizando que o vínculo afetivo estabelecido entre a mãe e o filho é fundamental para o desenvolvimento sadio da criança. Dessa forma, o amor materno, muitas vezes, esteve relacionado a um sentimento instintivo, inato e natural da mulher diante da condição de "ser mãe". Entretanto, para Menezes (2007, p.24), "o amor materno está longe de ser uma condição inata".

O estudo realizado por Badinter (1985) mostrou que o amor materno é um sentimento, podendo ser expresso de diversas maneiras, uma vez que as condutas maternas são diversificadas conforme a história, a cultura e o momento socioeconômico. A autora propõe pensar o amor materno como mais um sentimento humano e, como tal, frágil, incerto e falho. Assim, ele não necessariamente está presente em todas as relações da mãe com seu filho, nem enraizado à essência feminina. Ele pode ou não ser expresso e manifestado (Badinter, 1985). Para Weber (2009, p. 20), "o que existe não é instinto materno, mas o amor materno, sentimento adquirido que se estabelece pela disposição da pessoa em amar a criança". Assim, o vínculo afetivo estabelecido entre mãe e bebê não é natural, mas construído na relação.

A concepção da maternidade, fortemente influenciada pelo mito do amor materno, produz uma rede de significados que atrelam o ser boa mãe ao amor materno "natural" e à maternagem inata. Assim, as mães que rompem com esse modelo pré-estabelecido e decidem entregar seu filho para adoção transgridem o mito do amor materno e tendem a ser excluídas e culpabilizadas pela sociedade. Dessa forma, o não questionamento do mito do amor materno pode trazer consequências tanto à mãe quanto à criança, na medida em que tal relação é atravessada por mitos e crenças que constroem o imaginário social em torno da maternidade e da "boa mãe" (Motta, 2008). Diante disso, verifica-se a complexidade da temática, pois, em um determinado contexto histórico e social, o mito do amor materno contribuiu para reforçar a importância da figura materna na atenção e cuidados frente a seus filhos. Em contrapartida, atualmente, tal concepção pode levar a uma violação dos direitos da gestante e da criança, pois os profissionais da saúde podem interferir na decisão de uma mãe de entregar o filho, pautados em crenças oriundas do mito do amor materno.

\section{Estatuto da Criança e do Adolescente, Nova Lei Nacional da Adoção e as Equipes de Saúde}

As crianças e os adolescentes, durante muito tempo, não foram considerados sujeitos de direitos em condição peculiar de desenvolvimento. A Lei 8.069, de 13 de julho de 1990, denominada Estatuto da Criança e do Adolescente (ECA, Brasil, 1990), decorrente da Constituição Federal (Brasil, 1988), estabeleceu os direitos das crianças e dos adolescentes. 
Entre os seus direitos fundamentais, a convivência junto à família e à comunidade se destaca nas legislações. $\mathrm{O}$ artigo 19 do ECA estabeleceu que eles têm direito de ser criados, cuidados e educados no seio de sua família e, excepcionalmente, em família substituta. Nos artigos 92 e 100 do referido estatuto, a excepcionalidade e a provisoriedade do acolhimento institucional são estabelecidas. É assegurada à criança e ao adolescente a preservação dos vínculos familiares e a integração em família substituta quando esgotados os recursos de manutenção na família de origem ou extensa.

A fim de possibilitar a garantia dos direitos da criança e do adolescente, no ano de 2006, foi elaborado o Plano Nacional de Promoção, Proteção e Defesa do Direito de Crianças e Adolescentes à Convivência Familiar e Comunitária (Brasil, 2006), que visa, em suma, ao desenvolvimento pleno das famílias e à proteção aos vínculos familiares e comunitários. Entre os objetivos gerais estabelecidos no plano, encontram-se: ampliar, articular e integrar as diversas políticas, programas, projetos, serviços e ações de apoio sócio-familiar para a promoção, proteção e defesa do direito de crianças e adolescentes à convivência familiar e comunitária; difundir uma cultura de promoção, proteção e defesa do direito à convivência familiar e comunitária; e assegurar que o acolhimento institucional seja efetivamente utilizado como medida de caráter excepcional e provisório, proporcionando atendimento individualizado.

Outra conquista na esfera dos direitos da criança e do adolescente foi a promulgação, em agosto de 2009, da Lei $\mathrm{n}^{\circ}$ 12.010, conhecida como a "Nova Lei Nacional de Adoção" (Brasil, 2009), cujas determinações foram incorporadas ao ECA (Brasil, 1990). Ela preconizou acompanhamento psicológico e acolhimento judicial às gestantes ou mães que manifestarem a decisão de entregar seu filho para a adoção. Essas determinações poderão influenciar e promover os processos de adoção, visto que objetivam promover a garantia do direito da criança de estar em uma família (Brasil, 2009).

Frente às recentes recomendações da Nova Lei Nacional de Adoção (Brasil, 2009), mostra-se importante problematizar e refletir sobre a postura dos profissionais da saúde frente às mães que decidem entregar seus filhos. Será que estão preparados para lidar com essa situação? Estão capacitados para acolher a decisão da mulher sem julgá-la, garantindo assim seu direito? Profissionais de instituições de acolhimento institucional ou do poder judiciário, assim como médicos, enfermeiros e técnicos de enfermagem que entram em contato com as mulheres que decidem entregar seus filhos para adoção, precisam estar preparados para realizar esse acolhimento para que suas concepções pessoais não venham influenciar ou desrespeitar a mulher. Nesse sentido, opiniões, críticas veladas, comentários ou julgamentos podem interferir na decisão da mãe pela entrega, na medida em que os profissionais a impeçam, ou até mesmo tentem induzi-la ou coagi-la a não realizar a entrega de seu filho (Motta, 2008).

A neutralidade dos profissionais mostra-se importante para que não se force a entrega da criança em adoção, e para que não se force uma (re)ligação do interesse materno pela criança, evitando a entrega (Diniz, 1994). Assim, juízos de valor moral sobre o ato da mãe não auxiliam o processo nem promovem um acolhimento e encaminhamento da mãe e da criança. Dessa forma, a partir do arcabouço teórico da Teoria Bioecológica do Desenvolvimento Humano (TBDH), de Urie Bronfenbrenner (1979/1996, 2004), este estudo objetivou compreender como os profissionais de saúde manejam e conduzem os casos de mães que decidem entregar o filho para adoção, em maternidades de dois hospitais públicos, verificando o conhecimento desses profissionais sobre as leis que protegem as mulheres que entregam o filho para adoção e seu filho.

$\mathrm{Na}$ TBDH, os valores culturais, modos de vida, concepções sobre fenômenos e comportamentos, entre outros, fazem parte do que Bronfenbrenner (1979/1996, 2004) nomeou de macrossistema, um dos elementos do ambiente ecológico do ser humano em desenvolvimento. Estudar os aspectos macrossistêmicos dos fenômenos possibilita compreender o comportamento e planejar políticas públicas que visem a mudanças.

\section{Método}

\section{Delineamento e Participantes}

Trata-se de um estudo descritivo e exploratório, com abordagem qualitativa. Participaram sete profissionais da saúde (três técnicas de enfermagem, três enfermeiras e uma médica ginecologista e obstetra), funcionárias de dois hospitais públicos que desenvolvem atividades de ensino, pesquisa e extensão e que atendem pacientes pelo Sistema Único de Saúde (SUS) em uma cidade do interior do Rio Grande do Sul.

O critério de inclusão adotado para os participantes foi ser técnico de enfermagem, enfermeiro ou médico de uma maternidade pública. O único critério de exclusão foi o profissional ter filho(s) adotivo(s) pois a equipe de pesquisa avaliou que esse aspecto influenciaria a percepção sobre a mulher que entrega o filho. Todas as participantes foram mulheres, seu tempo de profissão variou de dois a 23 anos e o tempo de trabalho em maternidades variou entre cinco meses a 23 anos. Três profissionais eram casadas, uma encontravase em união estável, duas eram solteiras e uma, separada. Apenas uma participante não tinha filhos.

\section{Instrumentos}

Foram realizadas entrevistas semiestruturadas com as participantes do estudo. O roteiro da entrevista coletou informações sobre os dados biossociodemográficos das entrevistadas, como tempo de trabalho, idade, sexo, escolaridade, entre outras informações. O macrossistema, enquanto componente do ambiente ecológico descrito por Bronfenbrenner $(1979 / 1996,2004)$ foi foco da entrevista. Compõem o macrossistema de um indivíduo os valores, a cultura, as crenças e a visão de mundo de determinado grupo. Os aspectos macrossistêmicos presentes na fala das profissionais foram investigados e buscou-se compreender como eram conduzidos os casos de mães que decidiam entregar o filho para adoção. O conhecimento dos 
profissionais da saúde sobre as leis que protegem as gestantes e as suas crianças também foi verificado.

\section{Procedimentos e Considerações Éticas}

O projeto foi apresentado aos hospitais e uma autorização prévia foi emitida aos pesquisadores. De posse dessas autorizações, o projeto foi submetido ao Comitê de Ética em Pesquisa com Seres Humanos (CEP) de uma instituição de Ensino Superior para apreciação e avaliação. Com a aprovação do projeto de pesquisa pelo CEP, via Plataforma Brasil (protocolo número CAAE 04350412.0.0000.5346), os hospitais foram contatados novamente para que a apresentação do projeto às equipes das maternidades fosse realizada. Após todas as dúvidas esclarecidas, os profissionais que preencheram os critérios de inclusão foram convidados a responder à entrevista.

No momento da entrevista, foi solicitada a assinatura do Termo de Consentimento Livre e Esclarecido às participantes. As entrevistas foram realizadas individualmente em uma sala do hospital e tiveram duração de cerca de uma hora e 30 minutos. Todos os preceitos que regem a ética em pesquisas com seres humanos foram contemplados, como a garantia de confidencialidade das informações, sigilo das identidades dos participantes, o caráter voluntário da pesquisa e a garantia de que o profissional poderia desistir de sua participação na pesquisa em qualquer momento sem que houvesse prejuízo para si. Considerando que o estudo buscava explorar as concepções dos profissionais sobre o tema, esta pesquisa foi avaliada como de risco mínimo. As entrevistas foram realizadas por uma equipe de pesquisadores, que incluiu a coordenadora deste estudo e alunos da graduação e pósgraduação em Psicologia de uma instituição de ensino superior.

\section{Análise dos Dados}

Os dados foram analisados através do método de análise de conteúdo proposto por Bardin (1977/1979). Através da análise do material, foram definidas as categorias. As entrevistas foram transcritas e analisadas primeiramente de forma individual e posteriormente em conjunto, partindo-se para os elementos presentes nas mesmas, considerando-se a força discursiva, os sentimentos manifestados, os silêncios ou conflitos em relação à temática. Para garantir fidedignidade à análise, duas professoras doutoras em Psicologia com formação e trajetória consolidada na área foram convidadas a avaliar as falas e identificar à qual categoria pertenciam. Nesse processo, foram obtidos os percentuais de $80,25 \%$ e $61,3 \%$ de concordância entre as juízas, obtendo-se uma média satisfatória de 70,77\% de concordância. Assim, as categorias encontradas foram: (a) Características das mães que entregam o filho para adoção, (b) Manejo das profissionais diante da decisão de mães de entregar o filho para adoção, e (c) (Des) preparo da equipe de saúde. Os nomes e as respectivas profissões das entrevistadas foram codificados conforme o modelo: (A, enfermeira).

\section{Resultados e Discussão}

\section{Características das Mães que Entregam o Filho para Adoção}

Segundo as entrevistadas, a maioria das gestantes das maternidades dos dois hospitais públicos do município acessava exclusivamente o SUS. Na percepção das profissionais de saúde entrevistadas, as mães que decidiam entregar o filho para a adoção possuíam nível socioeconômico baixo, eram jovens com idades entre 14 e 24 anos e possuíam mais de um filho. É importante destacar que o perfil dessas mães não é diferente do perfil das usuárias que frequentam as maternidades dos hospitais públicos, como pode ser observado nos relatos: "geralmente de uma classe bem baixa" (C, enfermeira); "mas o que descreve bem é o pessoal mais de baixa renda, que procura o SUS" (A, técnica de enfermagem); "a gente pega uma faixa etária de jovens $e$ renda baixa também... A maioria, acho que $60 \%$ é em torno de 14 a 24 anos... que às vezes não é nem o primeiro filho, é o quarto, quinto..." (B, técnica de enfermagem).

Para as profissionais, entre os fatores implicados na decisão da entrega do filho para adoção, estavam presentes: a dependência química, problemas de saúde mental, prostituição, gravidez fruto de relacionamentos eventuais, gravidez indesejada e falta de recursos financeiros. Isso pode ser verificado através das falas: "com alguns problemas psicológicos e não sei se psiquiátricos também... Dependência química também que é uma coisa bem importante que está abrangendo bastante gestante, mais ou menos esse perfil assim" (C, enfermeira); "eu acho que são, né, mas aquelas que fazem programas (prostituição)..." (B, técnica de enfermagem); "normalmente [os motivos] são problemas psicológicos, ou psiquiátricos, né. Ou problemas de rejeição, por não ter família, por ela não ter condições financeiras pra sustentar o bebê. Geralmente tá relacionado a uma desestrutura por trás" (F, médica). Estudos sobre adoção têm revelado características semelhantes das mães que entregam seus filhos para adoção (Fonseca, 2012; Freston \& Freston, 1994; Menezes, 2007; Soejima \& Weber, 2008). Freston e Freston (1994), em uma pesquisa com 58 mulheres que realizaram a entrega de seus filhos recém-nascidos em uma enfermaria na cidade de Campinas, SP, encontraram que, na maioria dos casos, eram mulheres solteiras, com idade entre 20 e 29 anos, migrantes em Campinas, com ensino primário incompleto, sem trabalho fixo e cuja gravidez foi fruto de relações eventuais. As condições socioeconômicas desfavorecidas e as vivências de abandono familiar, social ou do parceiro também são situações que influenciam a decisão ou a intenção da mulher em entregar seu filho para adoção (Fernandes, Lamy, Morsch, Filho, \& Coelho, 2011; Freston \& Freston, 1994; Leão, Silva, \& Serrano, 2012; Menezes, 2007; Soejima \& Weber, 2008). Essas características biossocioeconômicas evidenciam a situação de vulnerabilidade em que essa população se encontra. Soejima e Weber (2008) avaliaram a qualidade da interação familiar percebida na infância por 21 mulheres que entregaram um ou mais filhos e por 21 mulheres que não entregaram filhos, utilizando-se da Escala de Qualidade de Interação Familiar 
(EQIF). No primeiro grupo, as mulheres retrataram a ausência afetiva, o pouco envolvimento e o baixo reforçamento positivo familiar, assim como a percepção de punições excessivas e de comunicação e clima conjugal negativo. Esses aspectos diferiram do segundo grupo de mulheres, pois a maioria deste grupo percebeu sua infância permeada por alguns momentos afetivos e de envolvimento. A partir disso, as autoras puderam inferir que as mulheres que abandonaram seus filhos advinham de uma situação afetiva carente e de pouco envolvimento familiar. As punições frequentes, percebidas pelas mulheres como excessivas, faziam parte de um contexto de negligência familiar, levando à conclusão de que a mãe/mulher que abandona seu filho vivenciou situações de abandono em sua infância. Já no estudo de Menezes (2007), as seis mães entrevistadas que haviam entregue um ou mais filhos para adoção falaram sobre as razões que contribuíram para a decisão da entrega. Na pesquisa, as participantes apresentaram considerações importantes, como o sentimento de impossibilidade para exercer a maternidade em função de dificuldades econômicas, bem como a ausência de apoio familiar e da figura materna, cuja relação era distante. A autora encontrou sofrimento por não poder nutrir e cuidar dos filhos e certo pesar e arrependimento pela entrega do filho em algumas mulheres. Amargura, insatisfação e infelicidade também apareceram nos relatos, no entanto, a autora acreditava que tais sentimentos não se referiram apenas à entrega do filho, mas também demonstravam o desamparo que essas mulheres ainda vivenciavam em suas realidades (Menezes, 2007; Menezes \& Dias, 2011).

Quanto à saúde das pacientes atendidas pelos hospitais públicos, as profissionais apontaram que, no momento do parto, estas se encontravam em boas condições de saúde física, mas consideraram que o pré-natal realizado pelas gestantes não tinha sido o mais adequado. Segundo as entrevistadas, a maioria das mulheres não realiza o acompanhamento preconizado pelo Ministério da Saúde, o que poderia trazer prejuízo para a gestante e o bebê, pois o pré-natal é fundamental para um parto seguro e para a saúde de mãe e filho: "a gente vê essa deficiência assim, no atendimento pré-natal" (F, médica); "aquele pré-natal que não orienta nada, então elas chegam aqui despreparadas, inseguras, sem saber como é que vai ser o parto" (E, enfermeira);

Olha uma coisa que a gente acha bem falho é o pré-natal na cidade, bem falho.... Elas contam o número de consultas que a paciente fez. Só que não é por aí. Porque, às vezes, tu vê que a paciente fez cinco consultas só verificando a pressão, nem o obstetra, não foi escutado, que é o batimento do bebê, né. Então tu vê assim o nivel de paciente que tu vê que elas têm uma carência nesse atendimento. Nessas horas, nesse cuidado, nessa explicação (A, técnica de enfermagem).

A maioria é um pré-natal ... porco, como se diz assim. Tem duas, três consultas, só que pra elas, elas já consideram como sendo um pré-natal... pra ser pré-natal, tem que ser no mínimo as 6 consultas do SUS, batidinho. E outras alegam também que elas vão no pré-natal, mas os médicos não anotam no cartão de gestante as consultas... (D, técnica de enfermagem).

As unidades integrantes do sistema de saúde devem garantir a atenção pré-natal e puerperal conforme os parâmetros do Ministério da Saúde (2005), dentre eles: a captação precoce das gestantes com realização da primeira consulta de pré-natal até 120 dias da gestação; a realização de, no mínimo, seis consultas de pré-natal; a escuta da mulher e de seus (suas) acompanhantes durante a atenção pré-natal, esclarecendo dúvidas e informando sobre os procedimentos a serem adotados. Os relatos das participantes indicaram que o cumprimento de tais parâmetros ainda é um desafio.

Quanto às dificuldades vivenciadas pelas mães atendidas nos hospitais públicos no que diz respeito ao exercício da maternidade, as profissionais acreditavam que estas estavam relacionadas a fatores como a carência de preparo durante o pré-natal, a falta de planejamento familiar, o pouco conhecimento, a falta de comprometimento do companheiro, as dificuldades financeiras e o elevado número de filhos. Isso pode ser observado nos relatos: "é a falta de estrutura a nivel de municipio pra que essa mulher assim... recorra diante dos problemas que surja... É a falta de empoderamento dessa mulher, é a falta de conhecimento..." (F, enfermeira);

Sabe, eu acho que é justamente assim, oh, uma consequência de coisas não planejadas, né, de dificuldades financeiras, porque que a gente vê assim que tem dois, três filhos em casa... Falta de comprometimento do marido, do esposo, do companheiro, né, que sobrecarrega a mulher demais, dai ele tem um filho atrás do outro, sem compromisso (C, enfermeira).

De acordo com as entrevistadas, a gestante, na maioria das vezes, independente da decisão de entregar o filho, chegava à maternidade acompanhada por um parente. Para uma das participantes, as gestantes compareciam à maternidade "normalmente com alguém, se não é o companheiro, é uma prima, uma amiga, uma mãe, geralmente tem alguém, são raríssimos os casos que elas ficam sozinhas" (C, enfermeira). Assim, pode-se verificar a presença da família ou de alguém da rede de apoio da gestante no momento do parto. Entretanto, nas situações em que existe a possibilidade da entrega de uma criança para adoção, apesar de a gestante chegar à maternidade acompanhada, nem sempre se pode afirmar que as famílias foram consultadas ou estavam presentes no momento da decisão. Sem poderem ou conseguirem compartilhar, anteriormente, essa possibilidade com alguém próximo ou da família e somando-se a isso o fato de nem sempre realizarem um acompanhamento pré-natal como o esperado, as gestantes podem manifestar essa decisão de entregar um filho para adoção apenas quando se encontram em trabalho de parto. Nesses casos, os profissionais da saúde, diretamente implicados, podem apresentar um conflito entre suas crenças pessoais e os procedimentos técnicos.

\section{Manejo das Profissionais diante da Decisão de Mulheres de Entregar o Filho para Adoção}

Todas as profissionais entrevistadas já vivenciaram situações em que a parturiente decidiu entregar o filho para adoção. Entretanto, essas situações não ocorrem com frequências nos hospitais, em sua percepção.

A legislação que preconiza o acolhimento e o acompanhamento das gestantes que manifestam desejo de entregar o filho para adoção não definiu como esses procedimentos devem ser realizados nos serviços de saúde (Brasil, 2009). O acolhimento realizado nos hospitais 
públicos do município ocorria através de "conversas", como relatou uma profissional: "a gente conversa bastante nesse caso..." (A, técnica de enfermagem). As participantes revelaram a importância de respeitar essa manifestação das mulheres e de oferecer apoio durante essas "conversas", embora tenham destacado, como uma de suas condutas, a tentativa de fazê-las reavaliar a decisão. Esse aspecto pode ser observado nas falas: “... acho que sempre é feito todo um trabalho pra mãe ficar com a criança... Eu acho que não é assim, quero dar e ponto, sabe" (F, médica); "a gente tenta assim dizer 'não, deixa passar uns dias, acalenta, fica com o nenê, olha, amamenta"” (D, técnica de enfermagem); "é um ser que tá vindo, né. E tu tem mais que acolher. 'E se veio pra ti, é pra ti'. Então, eu sempre procuro cuidar delas nesse sentido" (A, técnica de enfermagem).

A gente faz de tudo, assim, pra mudar a idéia, sabe. Faz de tudo, sabe, pra convencer essa mãe ao contrário... por que dai tu vai conversar com essa mãe, tu vai descobrir o porquê disso tudo. E nós acabamos convencendo ela ao contrário, às vezes. Ou então, tu acaba dizendo, mas porque ou faz assim, faz assado, sabe. (A, técnica de enfermagem)

Diante das falas, pode-se observar que o comportamento, as atitudes e o manejo das entrevistadas no exercício profissional estavam permeados pela não aceitação da renúncia da maternidade, ou seja, pela ideia de que as mulheres devem amar, cuidar e permanecer com seus filhos. Além disso, as profissionais verbalizaram que essas situações despertavam sentimentos na equipe como "vontade de levar a criança para casa" (F, enfermeira) e tristeza, como pode ser observado no relato: "É uma situação que mexe muito com a gente, como profissional. Gera uma... uma... uma tristeza, assim sabe... eu sinto como uma tristeza" (E, enfermeira). A cartilha da Associação dos Magistrados Brasileiros (2008), que aborda a atenção às mulheres que decidem entregar o filho para adoção, sugeriu que a escuta e análise das motivações da mãe que decide pela entrega são necessárias em um primeiro momento, devendo o profissional de saúde realizar o encaminhamento para profissional capacitado de forma rápida a fim de diminuir a angústia diante da situação. Assim, pode-se identificar que as concepções pessoais das entrevistadas, por vezes, interferiram no exercício profissional, pois essa diretriz não está sendo seguida. A partir dessas falas, é possível inferir que as crenças pessoais das participantes estão em sintonia com a ideia de que o amor materno é um sentimento inerente às mulheres, sendo a entrega de um filho para adoção algo que contradiz essa concepção. Quando as participantes conseguiam reverter algumas decisões, sentiam-se bem, como pode ser observado na fala: "Bá, é muito bom, quando consegue [reverter a decisão], tu te sente bem contigo mesma" (A, técnica de enfermagem).

A legislação brasileira garante o direito à gestante de decidir ficar ou não com o filho (Brasil, 2009). Além disso, a lei 12.010/2009 estabeleceu no artigo $4^{\circ}$ que "incumbe ao poder público proporcionar assistência psicológica à gestante e à mãe, no período pré e pós-natal, inclusive como forma de prevenir ou minorar as consequências do estado puerperal'. E, no artigo $5^{\circ}$, que a assistência também deverá ser prestada a gestantes ou mães que manifestem interesse em entregar seus filhos para adoção. Nesse contexto, as instituições de saúde, para garantir os direitos da gestante e da criança, precisam estar preparadas para prestarem esse atendimento.

O estudo realizado por Leão, Silva e Serrano (2012) ressaltou a importância de ofertar às mães que decidem entregar o filho para adoção um espaço que possibilite à elaboração de suas vivências, assim como da implantação de políticas públicas que garantam o apoio emocional e jurídico a elas. Um exemplo de atendimento é o serviço de psicologia da maternidade de um hospital de Santa Catarina. Pensando nas mães que decidem entregar os filhos, o serviço desenvolve um trabalho denominado maternagem, que consiste no acolhimento dos bebês nascidos na instituição, abandonados ou entregues para adoção. A maternagem visa assegurar o desenvolvimento emocional, físico e mental dos bebês, a partir da transmissão de afeto, carinho e atenção proporcionados pelos psicólogos e estagiários de psicologia do serviço (Boing \& Crepaldi, 2004). O trabalho visa também fazer a mediação entre o hospital e a família substituta, garantindo que o bebê não fique sozinho durante sua permanência no hospital ou na instituição de acolhimento, e seja encaminhado desses locais diretamente à mãe adotiva. No contato com a mãe/família que deseja entregar o filho para a adoção na maternidade do hospital, há uma conversa entre a psicóloga e a mãe a respeito de todos os aspectos que envolvem a decisão de entregar o filho para adoção. Segundo as autoras, não há julgamento nem influência na escolha, mas uma postura compreensiva e receptiva de atender ao desejo da mãe, encaminhando o bebê já para a maternagem e, posteriormente, à mãe adotiva/substituta. Dessa forma, há uma preocupação com a mãe e com o filho, dando suporte a ambos: acolhendo o desejo de entrega da mãe e, também, possibilitando a importante maternagem ao bebê, visto que as rupturas de cuidado nessa fase da vida podem deixar marcas no desenvolvimento infantil (Boing \& Crepaldi, 2004).

Apesar de, na prática, encontrarem dificuldades para manejar a situação, a maioria das participantes relataram conhecer os encaminhamentos que devem ser adotados. As equipes comunicaram os casos à assistente social das instituições de saúde, assim como ao conselho tutelar do município e ao sistema judiciário. A legislação vigente prevê a comunicação aos órgãos competentes nos casos de mães ou gestantes que decidam entregar os filhos para adoção para que todos os procedimentos legais sejam tomados, prevendo ainda uma multa ao médico, enfermeiro ou dirigente de estabelecimento de atenção à saúde de gestante que não efetuar imediatamente o encaminhamento à autoridade judiciária dos casos de que tenha conhecimento (Brasil, 2009).

As profissionais entrevistadas relataram conhecer os direitos das gestantes estabelecidos na legislação, mas assumiram ter pouco conhecimento sobre os direitos das crianças: "olha, da gestante, eu até tenho, da criança e do adolescente, às vezes, eu me socorro com a assistente social. Tenho que ler o tal do ECA, mas às vezes falta um pouquinho de tempo" (C, enfermeira). Os direitos estabelecidos nas legislações específicas, segundo as profissionais entrevistadas, são: "acho que o direito dessa criança ser bem tratada, o direito dessa mãe ser respeitada. É fundamental 
como mulher, como mãe, como tudo. $O$ direito do paciente ser respeitado" (A, técnica de enfermagem);

Da gestante, do atendimento, né. Tem que ter uma casa com saneamento básico para receber a criança, né, moradia própria, saneamento básico em casa. Do direito da criança também tem o aleitamento, né, que agora o governo dá, né, o leite, para quem não tem o leite, condições nutricionais, para morar, escola ... (B, técnica de enfermagem)

Hoje em dia, até a lei da adoção não permite isso, né. Que eu acompanhe uma criança intra-útero... tipo assim, você ta grávida e você não tem condições, quer estudar. E eu, não posso te dar um suporte pra ficar com a tua criança. Isso não existe mais, né. A lei da... da adoção é bem específica, tu tem que entrar numa fila de espera... (F, médica)

As equipes de saúde, diante de casos de mães que decidiram pela entrega do filho, também comunicaram e solicitaram a presença do profissional do serviço social e da psicologia. Esses profissionais são vistos pelas equipes da maternidade como um "apoio", como pode ser verificado no relato: "mas a gente tem apoio. Por exemplo, a gente tem assistente social da residência [referindo-se à residência multiprofissional existente no hospital], tem psicóloga... então a gente tem um apoio quando acontece alguma coisa, assim, a gente chama assistente social, a gente chama a psicóloga" (E, enfermeira). Essa fala demonstra que a complexidade da temática exige que seja desenvolvido um trabalho articulado e interdisciplinar nas maternidades públicas. Somente assim um atendimento adequado e eficaz às gestantes e às crianças será possível.

\section{(Des) preparo da Equipe de Saúde}

A percepção das entrevistadas sobre a assistência ofertada às gestantes que decidem pela entrega do filho após o parto foi de que há carência na assistência e no acolhimento. As seguintes falas denotam esta percepção: "eu acho que é bem pouco né, eu acho que recebem quase nada. Isso não acontece, deveria acontecer. Não, não recebem. De lado nenhum, né. Não tem quem dê suporte para elas. Daí elas podem se arrepender" (C, enfermeira);

No SUS, não. São rotuladas e marginalizadas. Sabe, eu acho, assim, que ninguém vai antes, ou vai atrás dessa mãe pra tentar resolver a história. De repente, até consegue virar a cabeça, fazer mudar. Ir até a instituição e fazer pegar de volta, não é verdade. Acho que até poderia ser feito isso. Mas é uma coisa tão sem preparo, sabe. Não quis, pronto, deu. (A, técnica de enfermagem)

Outro aspecto significativo apontado pelas entrevistadas refere-se ao despreparo técnico e a falta de embasamento teórico para qualificar a atuação nos casos em que as mães verbalizam a decisão da entrega do filho para adoção. As falas a seguir ilustram este aspecto.

Não, acho que ninguém está preparado para lidar com esta situação, que é uma questão bem complicada. É uma vida, né, uma decisão de uma vida inteira... A gente não estuda isso, muito difícil a gente falar sobre abandono, até quando toca nesse assunto, querem ir rápido pra fugir desse tema, não vai acontecer comigo, não vou precisar passar por isso. (B, técnica de enfermagem)
Eu acho que por não ser um momento muito, que não acontece muito, eu acho que a gente fica um pouco sem saber o que fazer. A gente não pode julgar, a gente não pode. Mas eu acho que o preparo mesmo não, eu acho que não, eu acho que faltaria um embasamento, como eu te digo, acho que falta embasamento para saber o que eu vou dizer para ela, que sim ou que não, eu não sei o que ela vive e o que passa na cabeça dela, quais são as condições. Agora o preparo realmente eu acho que não, falta algo para isso. A gente tenta conduzir da melhor forma em cada caso, mas a gente não sabe se é a melhor. (C, enfermeira)

As falas das participantes sugerem que há uma insegurança e uma formação acadêmica deficitária no que se refere à capacitação profissional para lidar com as questões que envolvam a temática abordada. Essa insegurança e o despreparo na formação profissional podem estar associados ainda à complexidade da temática, que mobiliza aspectos subjetivos e desconstrói a concepção idealizada do amor materno. Dessa forma, considera-se de extrema importância o treinamento e a capacitação periódicos dos profissionais da saúde sobre a temática, pois um atendimento adequado e humanizado livre de indução na decisão é um direito da gestante que deseja entregar o filho para adoção, assim como um direito da criança.

Através do estudo, também se pode identificar a carência de discussão entre as profissionais das maternidades diante dos casos de mães que decidem entregar o filho para adoção. As profissionais verbalizaram que esse espaço não era disponibilizado na maternidade devido à grande demanda de atendimentos. Dessa forma, os casos vivenciados foram apenas encaminhados para o outro profissional da equipe, não ocorrendo um diálogo entre os profissionais e, consequentemente, não ocorrendo procedimentos articulados.

A importância dos psicólogos e assistentes sociais nas equipes de maternidade também foi apontada pelas profissionais da saúde: "tu tem que ter uma avaliação da psicóloga, eventualmente da assistente social. Então não é uma equipe de pré-natal, com médicos e enfermagem que vai dar esse suporte pra paciente" (F, médica). O psicólogo inserido na maternidade pode ofertar o apoio tanto para a equipe de saúde como para a gestante e a criança. O psicólogo, através do conhecimento específico, pode disponibilizar à equipe da maternidade uma escuta especializada, bem como orientar os profissionais através do conhecimento científico na área da psicologia sobre gestação, nascimento e, mais especificamente, sobre a entrega e a adoção. Além disso, o profissional da psicologia pode prestar um atendimento psicológico à gestante e à família nas questões referentes à maternidade, relação mãe-bebê, entrega e adoção.

Neste estudo, foi possível identificar que, apesar de as instituições de saúde que integraram o estudo contarem com o apoio de psicólogos oriundos das equipes de residência integrada multiprofissional em saúde, as profissionais de saúde ressaltaram a necessidade do profissional da psicologia estar atuando junto às equipes da maternidade: "acho que na maternidade do SUS tinha que ter o psicólogo sempre trabalhando junto" (A, técnica de enfermagem). Diante da complexidade do tema, ações e intervenções que priorizem os direitos estabelecidos na legislação vigente podem ser possibilitadas através do olhar de profissionais de diversas 
áreas do conhecimento. Dessa forma, faz-se necessário um trabalho interdisciplinar nas maternidades.

\section{Considerações Finais}

A legislação vigente prevê a entrega do filho para a adoção nas maternidades, assim como recomenda o acompanhamento psicológico e o acolhimento judicial às gestantes ou mães que tomam essa decisão. Porém, entende-se que apesar de existir a legislação, ainda se faz necessário avançar no que tange à garantia dos direitos das gestantes e das crianças. Através deste estudo, pôde-se compreender como profissionais de saúde que atuavam em maternidades de hospitais públicos manejavam os casos de mães que decidem entregar o filho para adoção. Além disso, pode-se conhecer o perfil dessas mulheres, assim como o conhecimento dos profissionais sobre a legislação brasileira voltada para a proteção dos direitos das gestantes, mães e crianças.

Constatou-se que, apesar de não ocorrer com freqüência, todas as profissionais vivenciaram situações em que a parturiente decidiu entregar o filho para adoção. As mulheres que entregaram seus filhos para a adoção eram jovens que advinham de condições sócio-econômicas desfavorecidas e realizaram um pré-natal deficitário.

O acolhimento e o encaminhamento das gestantes que decidiram pela entrega do filho são procedimentos que ocorrem nas maternidades públicas. No estudo, a equipe tinha uma "conversa" com a mulher antes de acionar os órgãos de garantia dos direitos da mulher e da criança. Esta, muitas vezes, visou à tentativa de reverter a situação da entrega. Dessa forma, a crença pessoal e o juízo de valores morais, ou seja, os aspectos macrossistêmicos, encontraramse presentes na atuação profissional. Além disso, pôde-se identificar carência de respaldo teórico na prática profissional diante desses casos.

As profissionais que participaram do estudo conheciam os encaminhamentos que deviam realizar diante desses casos, como a comunicação do caso ao Conselho Tutelar e ao Juizado da Infância e Juventude. Entretanto, é necessário estar preparado para lidar com essas situações, para que se possa fazer mais que encaminhamentos, visto que o profissional deve ajudar a mãe a refletir sobre a decisão da entrega do filho para a adoção. O despreparo na atuação diante dessas situações evidenciado pelo relato das participantes confirma a necessidade de discutir essa temática junto às equipes de saúde, como também de incluir nas maternidades profissionais da psicologia e do serviço social capacitados para realizarem o acompanhamento da gestante e da criança junto com a equipe da maternidade. Além disso, destaca-se a importância de mais estudos no âmbito nacional que abordem essa temática a fim de fornecer aos profissionais da saúde embasamento teórico para as práticas realizadas nas maternidades.

Como limitação do estudo, pode-se considerar a inclusão de apenas duas maternidades. Um estudo que incluísse profissionais da saúde de hospitais privados poderia contribuir para a melhor compreensão do fenômeno entre pacientes que utilizam os diferentes tipos de hospital. Além disso, ouvir as mulheres que já entregaram o filho para adoção também poderia ser revelador, ao proporcionar a compreensão do fenômeno entre aquelas mães que entregam por avaliarem não ter condições, sejam emocionais ou financeiras, de criar o filho, ou por não desejarem assumir o papel de mãe e todas as atribuições que esse papel impõe.

É tempo de o tema da renúncia da maternidade entrar em pauta nas equipes de saúde envolvidas com esse fenômeno. É tempo de as equipes terem ciência da complexidade do fenômeno e da importância de estarem capacitados para lidar com ele. Somente com uma abordagem séria e humana é que se poderá auxiliar as mães nessa decisão e garantir seus direitos, como também os do bebê.

\section{Referências}

Aloi, J. A. (2009). Nursing the disenfranchised: Women who have relinquished an infant for adoption. Journal of Psychiatric and Mental Health Nursing, 16, 27-31.

Ariès, P. (1981). História social da criança e da família (D. Flaksman, trans.). Rio de Janeiro: Livros Técnicos e Científicos.

Associação dos Magistrados Brasileiros. (2008). Campanha da AMB em favor da adoção consciente. Cartilha para profissionais de saúde. São Paulo: Autor.

Badinter, E. (1985). Um amor conquistado: o mito do amor materno. Rio de Janeiro: Nova Fronteira.

Bardin, L. (1979). Análise de Conteúdo (L. A. Reto \& A. Pinheiro, trans.). Lisboa: Edições 70. Original publicado em 1977)

Bowlby, J. (1989). Uma base segura: Aplicações clínicas da teoria do apego (S. M. Barros, trans.). Porto Alegre: Artes Médicas. (Original publicado em 1988)

Boing, E., \& Crepaldi, M. A. (2004). Os efeitos do abandono para o desenvolvimento psicológico de bebês e a maternagem como fator de proteção. Estudos de Psicologia (Campinas), 21, 211-226.

Bronfenbrenner, U. (1996). A ecologia do desenvolvimento humano: Experimentos naturais e planejados (M. A. V. Veronese, trans.). Porto Alegre: Artes Médicas. (Original publicado em 1979)

Bronfenbrenner, U. (2004). Making human beings human: Bioecological perspectives on human development. London: Sage.

Brasil (1988). Constituição 1988. Dispõe sobre a Constituição da República Federativa do Brasil. Brasília: Diário Oficial da República Federativa da União.

Brasil (1990). Leis e decretos. Lei n.8069, de 13 de julho de 1990. Dispõe sobre o Estatuto da Criança e do Adolescente e dá outras providências. Brasília.

Brasil (2006). Plano nacional de promoção, proteção e defesa do direito de Crianças e adolescentes à convivência familiar e comunitária. Presidência da República, Secretaria Especial dos Direitos Humanos: Ministério do Desenvolvimento Social e Combate à Fome. 
Brasil (2009). Lei n 12.010, de 29 de julho de 2009. (2009). Dispõe sobre adoção; altera as Leis nºs 8.069, de 13 de julho de 1990 Estatuto da Criança e do Adolescente, 8.560, de 29 de dezembro de 1992; revoga dispositivos da Lei ${ }^{\circ} 10.406$, de 10 de janeiro de 2002 - Código Civil, e da Consolidação das Leis do Trabalho - CLT, aprovada pelo Decreto-Lei $n^{\circ} 5.452$, de $1^{\circ}$ de maio de 1943; e dá outras providências. Recuperado em 20/11/2012 de http://www.planalto.gov.br/ccivil_03/_Ato2007-2010/2009/ Lei/L12010.htm.

Condon, J. (1986). Psychological disability in women who relinquish a baby for adoption. The Medical Journal of Australia, 144, 117-119.

Diniz, J. S. (1994). A Adoção. In F. Freire (Ed.), Abandono e adoção: Contribuições para uma cultura da adoção (pp. 1330). Curitiba: Terre des Hommes.

Fernandes, R. T., Lamy, Z. C., Morsch, D., Filho, F. L., \& Coelho, L. F. (2011). Tecendo as teias do abandono: Além das percepções das mães de bebês prematuros. Ciência e Saúde Coletiva, 16, 4033-4042.

Fonseca, C. (2012). Mães "abandonantes": Fragmentos de uma história silenciada. Revista Estudos Feministas, 20(1), 13-32.

Freston, Y. M. B., \& Freston, P. (1994). A mãe biológica em casos de adoção: Um perfil da pobreza e do abandono. In F. Freire (Ed.). Abandono e adoção: Contribuições para uma cultura da adoção (pp. 81-90). Curitiba: Terre des Hommes.

Leão, L. C., Silva, C. G. C., \& Serrano, S. A. (2012). A entrega de um filho em adoção e as vicissitudes de ser mãe. Psicología para América Latina, 23, 28-46.
Menezes, K. F. F. L. (2007). Discurso de mães doadoras: Motivos e sentimentos subjacentes a doação (Unpublished master's thesis), Mestrado em Psicologia Clínica, Universidade Católica de Pernambuco.

Menezes, K. L., \& Dias, C. M. S. B. (2011). Mães doadoras: Motivos e sentimentos subjacentes à adoção. Revista Mal-estar e Subjetividade, 11(3), 933-960.

Ministério da saúde (2005). Pré-natal e puerpério atenção qualificada e humanizada: Manual técnico. Secretaria de Atenção à Saúde. Departamento de Ações Programáticas Estratégicas. Brasília: Ministério da Saúde.

Motta, M. A. P. (2008). Mães abandonadas: A entrega de um filho em adoção. São Paulo: Cortez.

Najman, J. M., Morrison, J., Keeping, D., Andersen, M., \& Williams, G. (1990). Social factors associated with the decision to relinquish a baby for adoption. Community Health Studies, 14, 180-189.

Soejima, C. S., \& Weber, L. N. D. (2008). O que leva uma mãe a abandonar um filho? Aletheia, 28, 174-187.

Weber, M. L. (2009). Bendita sois vós entre as mulheres: representações da mãe biológica acerca da entrega do filho em adoção. Monografia de Conclusão do Curso de Pós-Graduação em Enfrentamento da Violência contra Criança e Adolescente, Pontifícia Universidade Católica do Paraná, Curitiba.

Winnicott, D. W. (1999). Os bebês e suas mães (J. L. Camargo, trans.). São Paulo: Martins Fontes. (Original publicado em 1987) 